\title{
REVIEW
}

\section{Advances in adulteration and authenticity testing of turmeric (Curcuma longa L.)}

\author{
B Sasikumar ${ }^{1}$
}

Former Head, Division of Crop Improvement \& Biotechnology,

ICAR-Indian Institute of Spices Research, Kozhikode-673 012, Kerala.

E-mail: sasikumarsooranadu@gmail.com

Received 04 November 2019; Revised 13 December 2019; Accepted 30 December 2019

\begin{abstract}
Synthetic colorants such as metanil yellow, lead chromate, Acid orange 7, Sudan Red; rhizomes of related Curcuma sp. besides spent turmeric, starch, chalk and yellow soapstone are the main adulterants in traded turmeric while synthetic curcumin is an adulterant of natural curcumin. Both branded products as well as the produce from the unorganized sector are found adulterated. The adulterants, added either to increase the bulk, improve the colour and appearance or enhance the profit margin, often result in corroding the biological efficacy of the commodity and eroding the public impression besides posing health risks to the consumers. Various physical, chemical and PCR based methods are available to detect the adulterants in traded turmeric. While chemical methods are suited to detect the synthetic adulterants and spent turmeric, DNA based methods are the best options for detecting the biological adulterants (except spent turmeric) in the commodity. Along with adopting a supply chain system and quality linked pricing in turmeric trade, commercial adulteration diagnostic kits, if they can be developed and deployed, will be a very convenient way to ensure the quality of the traded produce.
\end{abstract}

Keywords: adulterants, detection, food safety, methods, supply chain, turmeric

\section{Introduction}

Spices are high value, export-oriented commodities and are extensively used for flavouring food and beverages as well as in medicine, cosmetics and perfumery. Traded forms of spices include dried or fresh whole commodity, powdered forms, pastes, dehydrated material, oils, oleoresin and extractives. Good quality spices are very relevant for the perceived biological efficiency of these commodities, their flavour or aroma.
The health-conscious public all over the world is increasingly looking for quality spices, be it for health, culinary or cosmetic uses. However, spices are often adulterated with inferior, similar-looking entities leading to erosion of the perceived biological value and public faith in these products.

Turmeric [Curcuma longa L. (Zingiberaceae)], already well known as a spice, a colouring agent for food, and cosmetic, is becoming increasingly important as a medicinal herb for its anti-

${ }^{1}$ Current Address : SEKT D6, Varada, Kurup's Lane, PO Sasthamangalam, Thiruvananthapuram-10, Kerala. 
inflammatory, anti-cancerous, anti-oxidant, antimicrobial, and anti-viral properties; as an antiseptic; and in the treatment of diabetes and Alzheimer's disease (Sasikumar 2005; Bejar 2018). Turmeric has a history of 5000 years as a herb in folk medicine as well as in Indian and Chinese systems of medicine. India is the largest producer, consumer, and exporter of turmeric, which is traded mainly in the form of wholedried rhizomes, as powder and as valued-added forms. In the powder form, which is mainly used in commerce and by the food, cosmetic and pharmaceutical industries, turmeric consists of particles approximately $0.2-0.25 \mathrm{~mm}$ in size (60-80 mesh). The powdered form has the highest share in exports, constituting about $42 \%$ of the world trade in turmeric. Many branded turmeric powders, besides the produce from the unorganized sector, are available in India and these products constitute the bulk of the domestic consumption of turmeric.

Recent reports on the medicinal value of turmeric in treating a variety of ailments have further increased the demand for turmeric all over the world. Major importers of turmeric powder are USA, UAE, Saudi Arabia, UK, Australia, and Canada. Consumer preference for natural /organic products has also spurred the demand for turmeric. Unfortunately, as common to other powdered spices, turmeric powder too is being adulterated, with filler materials, synthetic dyes, inert or biological entities, that go visually undetected while synthetic materials are the sole adulterants of the whole commodity (Singhal et al. 1997; Dhanya \& Sasikumar 2010) and the natural curcumin with the synthetic product. These adulterants/extraneous matters besides adding bulk and increasing appearance, result in diluting the main product and thereby making it less effective, which, in turn, erodes consumer confidence besides posing health hazards (synthetic colorants).

The Bureau of Indian Standards suggests a minimum of $3 \%$ curcumin for powdered turmeric, whereas the mandatory Prevention of Food Adulteration (PFA) Act of 1954 does not specify any minimum curcumin limit (Dixit et al.
2009). Despite the regulations in place in India, the quality of turmeric products in the Indian market is highly variable owing to a variety of reasons such as genotype, location and cultural practices (Sasikumar 2001). Adulteration is another reason for the variation in curcumin content of traded turmeric powder (Ali et al. 2019).

World organizations like the International Organization for Standardization (ISO), American Spice Trade Association (ASTA), The Food Safety and Standards Authority, India (FSSAI), impose strict regulations on the quality of spices and herbs imported and exported. The globalization of food trade requires the development of integrated approaches, such as traceability of origin, quality and authenticity to ensure food safety and quality (Barbuto et al. 2010). In the post-WTO era, importing countries, as well as the consumers, pay more and more attention to food quality, demanding clearer product traceability as well as the use of detailed and accurate product labels.

Adoption of a supply chain system in turmeric trade and quality linked pricing coupled with developing and deploying easy and fast adulteration detection kits are sure shots to ensure the quality of the traded turmeric.

\section{Adulterants in turmeric}

Adulteration may be defined as mixing or substituting the original material with other spurious, inferior, defective, spoiled, useless parts of the same or different plant, harmful substances or synthetic chemicals which do not conform with official standards. Adulteration can be in two ways- direct/intentional adulteration and indirect/unintentional adulteration. Direct/ intentional adulteration includes practices of substitution partially or fully with inferior materials owing to their morphological resemblance or chemicals or inert materials in order to attain financial gain. Unintentional adulteration results mainly from the absence of a proper evaluation method (Preethi et al. 2014; Bharathi et al. 2018) and clerical errors (Zhao 
et al. 2006).Though adulterants in turmeric are reported since the 1970s, adulterant detection in commercial turmeric products is of recent origin (Salmén et al. 1987; Sasikumar et al. 2004). The common adulterants in traded turmeric are given in Table 1.

\section{Techniques for adulterant detection}

Many techniques have been developed to detect adulteration in turmeric owing to the increased consumer awareness on food safety and quality control.

\section{Physical methods}

The physical methods involved microscopic observation and other parameters such as solubility, bulk density, texture etc.

\section{Microscopic analysis}

Details on the microscopic features of turmeric rhizome and other Curcuma species such as $C$. aromatica, C. xanthorrhiza, and C. zedoaria have been reported (Upton et al. 2011; Tandon et al. 2008; Eschrich 1999). However, the microscopic methods, in general, suffer from subjectivity, phenological variation, expressivity, lack of distinguishing markers, low throughput etc.

\section{Analytical methods}

Analytical techniques mainly use the chemical composition or organic components present in the plant for their identification and authentication. Depending on this basic principle, the techniques can be grouped into different types.

\section{Chromatographic techniques}

Thin-layer chromatography (TLC) is the simplest, most versatile and economical way of obtaining the chemical fingerprints of multiple herbal samples. Sen et al. (1974) described a method to detect the adulteration of Curcuma longa with $C$. zedoaria and C. aromatica that involves a three-step colour sequence for the detection of camphor and camphene, the active principles of these adulterants, which are absent in turmeric. Raghuveer et al. (1979) reported a thin layer-gas chromatographic method to detect C. aromatica admixture with common turmeric (C. longa). More recently, the HPTLC Association published a method to distinguish $C$. longa and C. xanthorrhiza (Anonymous 2017). The same method was earlier used to detect the adulteration of turmeric with C. aromatica (Booker et al. 2014).

Dixit et al. (2008) reported turmeric adulteration with synthetic dyes and detected the presence of organic dyes, such as metanil yellow (1.5-4.6 $\left.\mathrm{mg} \mathrm{g}^{-1}\right)$, Sudan I (4.8-12.1 $\left.\mathrm{mg} \mathrm{g}^{-1}\right)$, and Sudan IV $\left(0.9-2 \mathrm{mg} \mathrm{g}^{-1}\right)$ in loose turmeric and chilli samples from city markets across India. The curcumin content in turmeric and mixed curry powder samples ranged from 6.5 to $36.4 \mathrm{mg}$ $\mathrm{g}^{-1}$ and from 0.3 to $1.9 \mathrm{mg} \mathrm{g}^{-1}$, respectively. In a more detailed study by the same group, 712

Table 1. Common adulterants in traded turmeric/curcumin

\begin{tabular}{lll}
\hline Commodity & $\begin{array}{l}\text { Synthetic/chemical and non chemical } \\
\text { adulterant }\end{array}$ & Biological adulterant \\
\hline Turmeric whole/powder & Metanil yellow & Wild Curcuma sp. (C. zedoaria or C. \\
& Lead chromate & malabarica, . aromatica) \\
& Acid orange & Starch from cheaper source \\
& Sudan Red G & Sawdust \\
& Aniline & Spent turmeric powder \\
& Yellow soap stone & \\
& Chalk powder & \\
Curcumin & Synthetic curcumin & \\
\hline
\end{tabular}


commercial samples in India were tested using a two-dimensional high-performance thin-layer chromatography (HPTLC) method. None of the branded samples $(\mathrm{N}=100)$ showed the presence of artificial color, but 105 (17.2\%) of the nonbranded samples $(\mathrm{N}=612)$ of turmeric powders were dyed with metanil yellow (Dixit et al. 2009). Jaiswal et al. (2016) analysed 15 turmeric samples for synthetic adulterants by TLC and found that 10 out of 15 turmeric samples collected from Allahabad (now Prayag) were adulterated with metanil yellow, Sudan III and artificial colour.

A detailed study on the quality of 39 commercial turmeric samples for food, dietary supplement and cosmetic uses sold in supermarkets and retail stores in the United Kingdom (27), India (8), the Netherlands (2), Iceland (1), and Greenland (1) labeled to contain C. longa (34), C. amada (1), C. aromatica (2), C. xanthorrhiza (1), and C. kwangsiensis (1) by HPTLC showed that three products did not contain turmeric, one turmeric product was adulterated with $C$. aromatica, and one product from India contained merely curcumin, with little to no demethoxyand bisdemethoxy curcumin (Booker et al. 2014).

Gas chromatography can also be used to detect the presence of other Curcuma sp. in turmeric as many commercial turmeric dietary supplements contain essential oil in addition to the curcuminoids. There are substantial differences in the composition of the sesquiterpene fractions and lower amounts or absence of turmerones in some of the adulterating species (Raghuveer et al. 1979; Sasikumar 2005).

A number of HPLC methods have been used for the detection and estimation of curcuminoids as a tool for the evaluation of the quality of commercial ingredients and products. The methods include a variety of detection systems (UV, diode array, mass spectrometric, and fluorescence) and chromatographic techniques (HPLC, GC, CE) (Hong et al. 2017; Mudge et al. 2016; Rohman 2012; Lee \& Choung 2011). For typical turmeric extracts, HPLC chromatograms showing a characteristic fingerprint of the three curcuminoids in a consistent ratio ( $77 \%$ curcumin (Curcumin I) $\sim 17 \%$ demethoxycurcumin and $\sim 3 \%$ bisdemethoxy curcumin) has been, for many years, the approach to determine the product identity and quality (Li et al. 2011; Rohman 2012; Lee \& Choung 2011; Wichitnithad et al. 2009; Jayaprakasha et al. 2002). Bisdemethoxy curcumin is reportedly absent in C. aromatica and C. xanthorrhiza, allowing for a distinction from C. longa based on this compound (Booker et al. 2014; Anonymous 2017). Curcuma zedoaria has demethoxy curcumin as the main curcuminoid, contrary to C. longa where curcumin I is the most abundant curcuminoid (Avula et al. 2012; Thomas et al. 2011; Paramapojn et al. 2009). However, adulteration detection based solely on the curcuminoid profile may not be appropriate due to varietal, location and seasonal variations besides the solvent used in the curcuminoid profiling (Li et al. 2011).

\section{Spectroscopic analysis and chemo metrics}

Spectroscopy, the study of the interaction between electromagnetic radiation and matter, includes techniques like UV, visible, mid or near infrared (MIR, NIR), Raman, fluorescence, and nuclear magnetic resonance (NMR) that allow non-destructive testing and the use of small samples to achieve identification (Meuren 2010; Bharathi et al. 2018). Tiwari et al. (2013) using Laser-Induced Breakdown Spectroscopy (LIBS) analysed four commercial samples of whole dried rhizomes of turmeric collected randomly from four different areas of the spice market of Allahabad (Prayag), India, for possible adulteration. The analysis demonstrated that one of the four samples had spectral signatures corresponding to lead $(\mathrm{Pb})$ and chromium $(\mathrm{Cr})$, suggesting they might contain lead chromate as an adulterant providing color to make them more attractive to consumers.

${ }^{1} \mathrm{H}$ NMR spectroscopy-metabolomics has been used to identify Curcuma species and authenticate turmeric samples. Using this method it was possible to differentiate $C$. longa from $C$. aromatica and C. xanthorrhiza based on Principal Component Analysis (PCA). A 
contribution plot also allowed determination of the main curcuminoid differences among the Curcuma species (the absence of bisdemethoxy curcumin in C. aromatica and C. xanthorrhiza being one of the main distinguishing traits) and among $C$. longa extracts made with different solvents (Booker et al. 2014).

Fourier Transform-Raman (FT-Raman) and Fourier (FT-IR) spectroscopy are very useful in detecting metanil yellow in turmeric powder. Dhakal et al. (2016) demonstrated the application of FT-Raman and FT-IR spectroscopy in detecting metanil yellow in turmeric. These authors utilized Fourier Transform-Raman (FT-Raman) and Fourier Transform-Infra Red (FT-IR) spectroscopy as separate but complementary methods for detecting metanil yellow adulteration of turmeric powder. Simulated samples of turmeric powder and metanil yellow were prepared at concentrations of $30 \%, 25 \%, 20 \%, 15 \%, 10 \%, 5 \%, 1 \%$, and $0.01 \%(w / w)$. FT-Raman and FT-IR spectra were acquired for these mixtures as well as for pure samples of turmeric powder and metanil yellow. Spectral analysis showed that the FT-IR method could detect the metanil yellow at 5\% concentration, while the FTRaman method appeared to be more sensitive and could detect the metanil yellow at 1\% concentration. Relationships between metanil yellow spectral peak intensities and metanil yellow concentration were established using representative peaks at FT-Raman $1406 \mathrm{~cm}^{-1}$ and FT-IR $1140 \mathrm{~cm}^{-1}$ with correlation coefficients of 0.93 and 0.95 , respectively. The potential of a $1064 \mathrm{~nm}$ Raman chemical imaging system for the identification of azo color contamination in turmeric and curry powders were further studied by this group (Dhakal et al. 2018). Metanil yellow and Sudan-I, both azo compounds, were mixed separately with store-bought turmeric and curry powder at the concentration ranging from $1 \%$ to $10 \%(\mathrm{w} / \mathrm{w})$. Each mixture sample was packed in a shallow nickel-plated sample container (25 $\mathrm{mm} \times 25 \mathrm{~mm} \times 1 \mathrm{~mm}$ ). One Raman chemical image of each sample was acquired across the $25 \mathrm{~mm} \times 25 \mathrm{~mm}$ surface area using a $0.25 \mathrm{~mm}$ step size. A threshold value was applied to the spectral images of metanil yellow mixtures (at $1147 \mathrm{~cm}^{-1}$ ) and Sudan-I mixtures (at $1593 \mathrm{~cm}^{-1}$ ) to obtain binary detection images by converting adulterant pixels into white pixels and spice powder pixels into the black (background) pixels. The detected number of pixels of each contaminant is linearly correlated with the sample's concentration $\left(R^{2}=0.99\right)$. This study demonstrates the $1064 \mathrm{~nm}$ Raman chemical imaging system as a potential tool for food safety and quality evaluation.

The use of HPLC-MS provides even lower sensitivity with a limit of detection of as little as $100 \mathrm{pg} \mathrm{mL}^{-1}$ metanil yellow in turmeric powder (Feng et al. 2011). Fourier Transform Near-Infrared (FT-NIR) spectroscopy coupled with chemometrics was also used to detect corn starch illegally added to turmeric powder, using simulated samples (Kar et al. 2019a). In this work, the pure turmeric powders were blended with corn starch to generate different concentrations $(1-30 \%)(w / w)$ of starch-adulterated turmeric samples. The reflectance spectra of a total of 224 samples were taken by FT-NIR spectroscopy. The exploratory data analysis was done by Principal Component Analysis (PCA). The starch related peaks were selected by Variable Importance in Projection (VIP) method and were explored by examination of original reflectance spectra, $1^{\text {st }}$ derivative spectra, PCA loadings and $\beta$ coefficients plot of the Partial Least Square Regression (PLSR) model. The coefficient of determination $\left(\mathrm{R}^{2}\right)$ and root-mean-square error of partial least square regression (PLSR) models were found to be $0.91-0.99$ and $0.23-1.3 \%$, respectively, depending on the pre-processing techniques of spectral data. The Figure Of Merit (FOM) of the model was found with the help of the Net Analyte Signal (NAS) theory. These authors recently estimated the potential of NearInfra Red (NIR) spectroscopy coupled with chemometrics as a rapid and non-destructive tool for the detection as well as quantification of Sudan dye I adulterated turmeric powder using simulated samples. The concentrations of the adulterants were $0.05 \%, 0.1 \%, 0.2 \%, 0.5 \%$, $1 \%, 1.5 \%, 2 \%, 5 \%, 10 \%, 15 \%, 20 \%, 25 \%$ and $30 \%$ $(\mathrm{w} / \mathrm{w})$, respectively. Exploratory data analysis 
was done for the visualization of the adulterant classes by Principal Component Analysis (PCA). In the classification approach, Principal Components (PCs) extracted by PCA were fed as the inputs of the Support Vector Machine (SVM) classifier. The average accuracy of the adulterants classes noted was greater than $90 \%$ (Kar et al. 2019b).

Using Atomic Absorption Spectroscopy (AAS), Quratey \& Kwarkey (2018) reported the highest level of chromium in turmeric samples amongst ten spices collected from the Ghana market. Turmeric recorded the highest mean $\mathrm{Cr}$ concentration $\left(0.42 \pm 0.03 \mathrm{mg} \mathrm{kg}^{-1}\right)$. Nallappan et al. (2013) used terahertz spectroscopy, a non-intrusive method, to effectively identify adulteration of turmeric with chalk powder in packed produce.

\section{PCR based molecular methods}

Polymerase Chain Reaction (PCR) has a high potential in biological adulterant detection and authentication of commodities due to its simplicity, sensitivity, specificity as well as rapid analysis time and low cost (Sasikumar et al. 2016; Swetha et al. 2016; Dhanya \& Sasikumar 2011; Mafra et al. 2008; Vidal et al. 2007).

PCR based adulteration detection in turmeric has been started by our group as early as 2004. Sasikumar et al. (2004), analysed three popular market samples of branded turmeric powder from the Indian market using Random Amplified Polymorphic DNA [RAPD] analysis and revealed the presence of $C$. zedoaria in the samples though the curcumin levels of the samples met the quality standards. Dhanya et al. (2011) developed RAPD based Sequence Characterized Amplified Region (SCAR) markers to detect plant-based adulterants in traded turmeric. Six samples of branded turmeric powder procured from a local market at Calicut (Kozhikode), Kerala, India were analyzed using the two SCAR markers and both markers detected the presence of adulteration with C. zedoaria or C. malabarica in four out of six market samples and in simulated mixtures, i.e., samples of turmeric powder and the adulterants made at different concentrations. Parvathy et al. (2015) successfully used the DNA barcoding locus ITS to detect the plant-based adulterants in commercial samples of branded turmeric powder. Though band level discrimination of the adulterants and the genuine sample was not possible, single nucleotide polymorphisms (SNPs) related to the adulterants and genuine product was observed (Table 2). One out of the 10 samples analysed was found adulterated with C. zedoaria.

\section{Radiotracer techniques}

After the first report of adulteration of natural curcumin with synthetic curcumin in 2011, research on using radiocarbon dating techniques to analyze curcumin products on the market to determine the percentage that contained synthetic versus natural curcumin, or a combination of both gained momentum (Rafi 2016; Watson 2011; Krishnakumar \& Sanandakumar 2011). The ${ }^{14} \mathrm{C}$ testing of five commercial samples of curcumin showed that four of the materials contained curcumin that was $32-45 \%$ synthetic, while the fifth sample was 100\% natural (Press release -Sabinsa, 2015). Using the same testing approach other commercial samples too were analysed for synthetic curcumin (Anonymous 2017).

\section{Miscellaneous techniques}

Sen et al. (2017) developed physical and chemical methods to detect yellow lead salt chalk, metanil yellow, aniliue dye and starch in turmeric powder.

\section{Future perspectives and conclusion}

Turmeric powder and turmeric extracts are valued both for their medicinal properties and as a culinary spice. Turmeric-based dietary supplements (which also include standardized extracts with high concentrations of curcumin) have seen a steady increase in popularity globally. In the United States, the largest market for turmeric supplements, sales have almost 
Table 2. SNPs that discriminate between C. longa and C. zedoaria

\begin{tabular}{ccccc}
\hline Species & \multicolumn{4}{c}{ Position of SNP and nucleotide substituted } \\
\hline C. longa & 293 & 388 & 410 & 439 \\
C. zedoaria & G & G & G & G \\
\hline
\end{tabular}

Source: Parvathy et al. (2015)

tripled from 2013 to 2016, totaling over US \$69 million in 2016. Unfortunately this high value, low volume commodity, has been subjected to deliberate, economically-motivated adulteration leading to reduced perceived biological value and posing health risks besides eroding public faith. Adulteration is also a major economic fraud involving public health. Reliable, easy, sensitive and high throughput traceability and authentication methods coupled with quality standards thus assume significance. Adoption of a supply chain practice in turmeric trade and quality linked pricing in addition to commercial adulteration diagnostic kits, if they can be developed and deployed, will be a sure shot to ensure the quality of the traded produce.

\section{References}

Ali Z, Saleem M, Atta B M, Khan S S \& Hamma G 2019 Determination of curcuminoid content in turmeric using fluorescence spectroscopy. Spectrochim. Acta A: Mol. Biomol. Spectrosc. 213: 192-198.

Amel B 2015 Microscopic analysis of Curcuma longa L. using multivariate test. Int. J. Pharmacogn. 2: 173-177.

Anonymous 2017 Turmeric rhizome (Curcuma longa). HPTLC Association. http://www.hptlcassociation.org/methods.cfm.

Avula B, Wang Y H \& Khan I A 2012 Quantitative determination of curcuminoids from the roots of Curcuma longa, Curcuma species and dietary supplements using an UPLC-UV-MS method. J. Chromatogr. Sep. Tech. 3: 120.

Barbuto M, Galimberti A, Ferri E, Labra M, Malandra R \& Galli P 2010 DNA barcoding reveals fraudulent substitutions in shark seafood products: The Italian case of "palombo" (Mustelus spp.). Food Res. Int. 43: 376-381.

Bejar E 2018 Turmeric (Curcuma longa) Botanical Adulterants Bulletin www. botanicaladulterants.org.

Bharathi S K V, Sukitha A, Moses J A \& Anandharamakrishnan C 2018 Instrument - based detectin methods for adulteration in spice and spice products- A review. J. Spices Arom. Crops 27: 106-118.

Booker A, Frommenwiler D, Johnston D, Umealajekwu C, Reich E \& Heinrich M 2014 Chemical variability along the value chains of turmeric (Curcuma longa): A comparison of nuclear magnetic resonance spectroscopy and high performance thin layer chromatography. J. Ethnopharmacol. 152: 292-301.

Dhakal S, Chao K, Kim M, Qin J \& Bae A D 2018 Detection of color dye contamination in spice powder using $1064 \mathrm{~nm}$ Ramanchemical imaging system. Proc. Sensing for Agriculture and Food Quality and Safety X: 1066509.

Dhakal S, Chao K, Schmidt W, Qin J, Kim M \& Chan D 2016 Evaluation of turmeric powder adulterated with metanil yellow using FTRaman and FT-IR spectroscopy. Foods 5: 36.

Dhanya K \& Sasikumar B 2011 Molecular marker based adulteration detection in traded food and agricultural commodities of plant origin with special reference to spices. Curr. Trends Biotechnol. Pharm. 4: 454-489.

Dhanya K, Syamkumar S, Siju S \& Sasikumar B 2010 Sequence characterized amplified region markers: A reliable tool for adulterant detection in turmeric powder. Food Res. Int. 44: 2889-2895. 
Dixit S, Purshottam S K, Khanna S K \& Das M 2009 Surveillance of the quality of turmeric powders from city markets of India on the basis of curcumin content and the presence of extraneous colours. Food Addit. Contam. Part A. 26: 1227-1231.

Dixit S, Khanna S K \& Das M A 2008 A simple 2-directional high-performance thinlayer chromatographic method for the simultaneous determination of curcumin, metanil yellow, and Sudan dyes in turmeric, chilli, and curry powders. J. AOAC Int. 91: 1387-1396.

Eschrich W 199 Pulver-Atlas der Drogen. $7^{\text {th }}$ Ed. Stuttgart, Germany: Deutscher Apotheker Verlag.

Feng F, Zhao Y, Yong W, Sun L, Jiang G \& Chu X 2011 Highly sensitive and accurate screening of dyes in soft drinks by liquid chromatography-electrospray tandem mass spectrometry. J. Chromatogr. B. 879: 1813-1818.

Hong E, Lee S Y \& Jeong J Y 2017 Modern analytical methods for the detection of food fraud and adulteration by food category. J. Sci. Food Agri. 97: 3877-3896.

Jaiswal S, Yadav D S, Mishra M K \& Gupa A K 2016 Detection of adulterants in spices through chemical method and thin layer chromatography for forensic consideration. Int. J. Dev. Res. 6: 8824-8827.

Jayaprakasha G K, Jagan Mohan Rao L \& Sakariah K K 2002 Improved HPLC method for the determination of curcumin, demethoxycurcumin, and bisdemethoxycurcumin. J. Agri. Food Chem. 50: 3668-3672.

Kar S, Tudu B \& Bandyopadhyay R 2019a Identification and classification of Sudan dye adulterants in turmeric powder by NIR spectroscopy and support vector machine. Proc. IEEE International Symposium on Olfaction and Electronic Nose (ISOEN), 26-29 May 2019, Fukuoka, Japan.
Kar S, Tudu B, Jana A \& Bandyopadhyay R 2019b FT-NIR Spectroscopy coupled with multivariate analysis for detection of starch adulteration in turmeric powder. Food Addit. Contam. Part A, Chem Anal Control Expo Risk Assess. 36: 863-875.

Krishnakumar P K \& Sanandakumar S 2011 User industries trade in synthetic substitutes for costly commodities. The Economic Times, February 24, 2011.

Lee J H \& Choung M G 2011 Determination of curcuminoid colouring principles in commercial foods by HPLC. Food Chem. 124: $1217-1222$.

Li S, Yuan W, Deng G, Wang P, Yang P \& Aggarwal B 2011 Chemical composition and product quality control of turmeric. Pharm. Crops 2: 28-54.

Mafra I, Ferreira, I M P L V O \& Oliveira M B P 2008 Food Authentication by PCR based methods. Eur. Food Res. Tech. 227: 649-655.

Meuren M 2010 Spectrophotometric techniques. In: Lees M (Ed.), Food authentication and traceability. Wood head publishing, Cambridge, pp.184-185.

Mudge E, Chan M, Venkataraman S \& Brown P N 2016 Curcuminoids in turmeric roots and supplements: Method optimization and validation. Food Anal. Methods 9: 1428-1435.

Nallappan K, Dash J, Ray S \& Pesala B 2013 Identification of adulterants in turmeric powder using terahertz spectroscopy. Proc. $38^{\text {th }}$ Int. Conf. on Infrared, millimeter and tetrahertz waves, 1-6 Sept. 2013, Mainz, Germany.

Nath P, Sarkar K, Tarafder P, Mondal M, Das M \& Paul G 2015 Practice of using metanil yellow as food colour to process food in unorganized sector of West Bengal - A case study. Int. Food Res. J. 22: 1424-1428.

Paramapojn S \& Gritsanapan W 2009 Free radical scavenging activity determination and 
quantitative analysis of curcuminoids in Curcuma zedoaria rhizome extracts by HPLC method. Curr. Sci. 97: 1069-1073.

Parvathy V A, Swetha V P, Sheeja T E \& Sasikumar B 2015 Detection of plant based adulterants in turmeric powder using DNA barcoding. Pharm Biol. 53: 1774-1779.

Preethi P J, Padmini, K, Lohitha, M, Swetha, K, Priyanka K \& Rao V P 2014 Adulterants and substitutes of foods and herbs: A review. Int. J. Med. Chem. Anal. 4: 213-217.

Press Release 2015 Sabinsa takes action against synthetic curcumin. Bangalore, India: Sabinsa Corporation 2015.

Quratey A \& Kwarkey N 2018 Heavy metal contaminants of selected culinary herbs and spices available in some Ghanaian markets. http://hdl.handle.net/123456789/11601.

Rafi M M 2016 Natural curcumin of turmeric origin - the untold story. Natural Products Insider [White Paper]: Informa Exhibitions, LLC.1-11.

Raghuveer K G \& Govindarajan V S 1979 Detection of admixtures of turmeric, Curcuma longa Linn., with Curcuma aromatica Salisb. by thin layer and gas-liquid chromatography [Adulteration]. J. AOAC Int. 62: 1333-1337.

Rohman A 2012 Analysis of curcuminoids in food and pharmaceutical products. Int. Food Res. J. 19: 19-27.

Salmén R, Fjærtoft Pedersen B \& Malterud K E 1987 Sudanrot G alsZusatz in Gelbwurzel (Curcuma longa L.). Z Lebensm Unters Forsch. 184: 33-34.

Sasikumar B 2001 Turmeric. In: Peter K V (Ed.), Handbook of herbs and spices. Vol. 1, Wood head publishing Ltd. Cambridge, pp.297-308.

Sasikumar B 2005 Genetic resources of Curcuma: diversity, characterization and utilization. Plant Genet. Res. - Conserv. Utiliz. 3: 130-151.

Sasikumar B, Swetha V P, Parvathy V A \& Sheeja
T E 2016 In: Downey G (Ed.), Advances in adulteration and authenticity testing of herbs and spices. Advances in food authenticity testing: Improving quality throughout the food chain, Wood head Publishing/Elsevier, pp.585-612.

Sasikumar B, Syamkumar S, Remya R \& Zachariah T J 2004 PCR based detection of adulteration in the market samples of turmeric powder. Food Biotechnol. 18: 299-306.

Sen A R, Gupta P S \& Dastidar N G 1974 Detection of Curcuma zedoaria and Curcuma aromatica in Curcuma longa (turmeric) by thin-layer chromatography. Analyst 99: 153-155.

Sen S, Mohanty P \& Vuppu S 2017 Detection of food adulterants in chilli, turmeric and coriander powders by physical and chemical methods. Res. J. Pharmacy Tech. 10: 3057-3060

Singhal R S, Kulkarni P R \& Rege D V (Eds.) 1997 Handbook of indices of food quality and authenticity. Woodhead Publishing Ltd, Cambridge.

Sólyom A M 2009 A single laboratory validation study for the determination of curcuminoids in dietary supplements and foods by rapid resolution HPLC using PDA detection. $123^{\text {rd }}$ AOAC International Annual Meeting and Exposition. Philadelphia, PA.

Swetha V P, Sheeja T E \& Sasikumar B 2016 DNA Barcoding as an authentication tool for food and agricultural commodities. Curr. Trends Biotechn. Pharm. 10: 384-402.

Tandon N, Sharma P \& Gupta A K (Eds.) 2010 Curcuma longa Linn. In: Quality standards of Indian medicinal plants, Vol 8. New Delhi, India: Indian Council of Medical Research, pp.138-148.

Thomas E, Zachariah T J, Syamkumar S \& Sasikumar B 2011 Curcuminoid profiling of Indian turmeric. J. Med. Arom. Plant Sci. 33: 36-40.

Tiwari M, Agrawal R, Pathak A K, Rai A K \& Rai G K 2013 Laser-Induced breakdown spectroscopy: an approach to detect adulteration in turmeric. Spectroscopy Lett. 46: 155-159. 
Upton R, Graff A, Jolliffe G, Länger R \& Williamson E 2011 American herbal pharmacopoeia: Botanical pharmacognosy- Microscopic characterization of botanical medicines. Boca Raton, FL: CRC Press.

Vidal A O, Schnerr H, Rojmyr M, Lysholm F \& Knight A 2007 Quantitative identification of plant genera in food products using PCR and pyrosequencing technology. Food Control 18: 921-927.

Watson E 2011 Europharma to launch probe into synthetic vs. natural curcumin. Nutra
Ingredients-USA [online]: William Reed Business Media Ltd.

Wichitnithad W, Jongaroonngamsang N, Pummangura S \& Rojsitthisak P 2009 A simple isocratic HPLC method for the simultaneous determination of curcuminoids in commercial turmeric extracts. Phytochem. Anal. 20: 314-319.

Zhao Z, Hu Y, Liang Z, Yuan J P, Jiang Z \& Leung K S 2006 Authentication is fundamental for standardization of Chinese medicines. Planta Med. 72: 865-874. 